\title{
SISTEM PENGATUR IRIGASI SAWAH MENGGUNAKAN METODE IRIGASI ALTERNATE WETTING AND DRYING BERBASIS TEKNOLOGI INTERNET OF THINGS
}

\author{
Tisnainil Husna, Dody Ichwana Putra, Werman Kasoep \\ Jurusan Sistem Komputer, Universitas Andalas, Padang, 25163
}

\section{ARTICLE INFORMATION}

Received: August 07, 2018

Revised: September 9, 2018

Available online: September 29, 2018

\section{KEYWORDS}

Rice Field Irrigation, AWD Irrigation,

Regulating System, ESP8266, Ultrasonic

System, RTC, DS04 Motor, NFC, Smartphone

\section{CORRESPONDENCE}

E-mail: dody.ichwana@fti.unand.ac.id

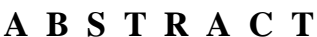

Rice is the staple food of the majority of Indonesians and most of the population work as farmers. However, the amount of rice produced are still insufficient. To meet the rice needs for the society, it should increase the amount of rice production by focusing on rice field quality such as the water level rice fields. In this study a prototype rice field irrigation system is designed using AWD irrigation method by regulating open activation and closing the inlet gate and exit gate based on the age of paddy which are calculated using RTC and the height of paddy water measured using ultrasonic sensors. The system also designed to receive input from the age of paddy and deactivate the system from the mobile application through the ESP8266 module. Test results from this system can measure water level with accuracy of $95.68 \%$ and read real-time time with $98.67 \%$ accuracy. The servo motor NFC DS04 works to open the door with a duration of 60 seconds and closes the door with a duration of 56 seconds. The paddy irrigation regulating system can regulate the water level with a success percentage of $81.48 \%$. The system can receive input and deactivate the system with a percentage of success of $70 \%$.

Salah satu metode irigasi hemat air adalah metode irigasi Alternate Wetting and Drying (AWD). Pada pengamatan metode irigasi air sawah menggunakan metode irigasi berbeda, penghematan air menggunakan metode AWD dapat menghemat air 55,03\%[5]. Pada pengkajian peningkatan produksi dan nilai ekonomi di desa Mario, Kec. Tanasitolo Sulawesi Selatan dengan metode irigasi yang berbeda dan nilai ekonomi yang sama memperoleh hasil produksi berbeda. Metode irigasi dengan menggunakan metode AWD menghasilkan produksi padi lebih banyak dari pada metode intermitten atau berselang dan irigasi terus menerus. Hasil produksi padi menggunakan metode irigasi AWD, intermitten dan terus-menerus secara berurut, yaitu Rp16,1 juta/ha, 14,1 juta/ha dan 13,4 juta/ha [3]. Dari data tersebut, diketahui bahwa metode irigasi AWD dapat diterapkan untuk meningkatkan produksi padi di lahan sawah.

Berdasarkan permasalahan di atas, maka dirancanglah sistem pengatur irigasi pada lahan sawah menggunakan metode irigasi AWD yang dapat mengatur kadar air di lahan sawah dan mengirim informasi ke smartphone. Tujuan yang ingin dicapai dari penelitian ini yaitu dapat mengatur pintu masuk dan keluar air secara otomatis menggunakan motor servo berdasarkan kadar air di lahan sawah, sistem pengatur irigasi yang dapat mengatur tinggi air di lahan sawah menggunakan metode irigasi AWD dan 
dapat meng-input-kan usia tanaman padi dan menonaktifkan sistem dari aplikasi mobile pada smartphone petani.

\section{LANDASAN TEORI}

\section{Irigasi AWD}

Alternate Wetting and Drying (AWD) atau sistem pergiliran basah dan kering merupakan suatu sistem pengairan sawah yang menghemat air dan dapat diterapkan oleh petani untuk mengurangi kebutuhan air irigasi di lahan sawah tanpa mengurangi hasil panen. Di dalam sistem pergiliran basah dan kering, air irigasi diberikan beberapa hari setelah hilangnya air yang tergenang sampai zona akar masih dapat menyerap air. Secara keseluruhan kondisi tinggi air pada irigasi AWD dibagi menjadi tiga kondisi, yaitu kondisi tergenang, kondisi AWD dan kondisi kering. Kondisi tergenang dimulai sejak usia tanaman padi berusia 1 HST (Hari Setelah Tanam) sampai 10 HST. Batas minimal tinggi air pada kondisi tergenang adalah $00 \mathrm{~mm}$ dari permukaan tanan dan tinggi air maksimal adalah $20 \mathrm{~mm}$ di atas permukaan tanah. Kondisi AWD dimulai saat usia tanaman padi berusia 11 HST sampai 10 hari sebelum usia panen tanaman padi. Batas minimal tinggi air pada kondisi AWD adalah $150 \mathrm{~mm}$ dibawah permukaan tanah dan batas maksimal tinggi air adalah $20 \mathrm{~mm}$ diatas permukaan tanah. Sedangkan kondisi tidak dilakukan pengisian air ke lahan sawah sampai usia tanaman padi dapat dipanen [4].

\section{Drainase Sawah}

Drainase adalah sistem pembuangan air yang dilakukan baik secara alami atau buatan dari permukaan atau bawah permukaan suatu tempat. Pembuangan ini dapat dilakukan dengan cara mengalirkan, menguras, membuang atau mengalihkan air ke tempat-tempat tertentu. Irigasi dan drainase merupakan bagian penting dalam sistem penyediaan air di bidang pertanian. Pada bidang pertanian, drainase sangat penting untuk mengatur tata air dalam tanah atau dalam zona perakaran tanaman dan mejadikan lingkungan mikroorganisme tanah lebih baik. Lingkungan mikroorganisme tanah yang baik dapat membantu kesuburan tanah karena mikroba akan membentuk senyawa-senyawa yang dibutuhkan tanaman. Drainase dilakukan untuk mengalirkan kelebihan air hujan, air pengairan (irigasi) atau genangan air lain dari suatu lahan usaha tani [5].

\section{Pertumbuhan Padi}

Padi merupakan tanaman pangan berupa rumput berumpun. Tanaman pertanian kuno berasal dari dua benua yaitu Asia dan Afrika Barat tropis dan subtropis. Bukti sejarah memperlihatkan bahwa penanaman padi di Zhejiang (Cina) sudah dimulai pada 3.000 tahun SM. Fosil butir padi dan gabah ditemukan di Hastinapur Uttar Pradesh India sekitar 100-800 SM. Selain Cina dan India, beberapa wilayah asal padi adalah, Bangladesh Utara, Burma, Thailand, Laos, Vietnam[6]. Di Indonesia, padi merupakan komoditas tanaman paling penting. Padi menjadi sumber bahan makanan pokok untuk sebagian besar penduduk Indonesia.

Pertumbuhan padi dibagi ke dalam tiga fase: (1) vegetatif (awal pertumbuhan sampai pembentukan bakal malai/primordial); (2) reproduktif (primordial sampai pembungaan); dan (3) pematangan (pembungaan sampai gabah matang). Fase vegetatif merupakan fase pertumbuhan organ-organ vegetatif, seperti pertambahan jumlah anakan, tinggi tanaman, jumlah, bobot, dan luas daun. Fase reproduktif ditandai dengan (a) memanjangnya beberapa ruas teratas batang tanaman; (b) berkurangnya jumlah anakan (matinya anakan tidak produktif); (c) munculnya daun bendera; (d) bunting; (e) pembungaan. Di daerah tropik, untuk kebanyakan varietas padi, lama fase reproduktif umumnya 35 hari dan fase pematangan 30 hari. Perbedaan masa pertumbuhan (umur) hanya ditentukan oleh lamanya fase vegetatif. Sebagai contoh, IR64 yang matang dalam 110 hari mempunyai fase vegetatif 45 hari, sedangkan IR8 yang matang dalam 130 hari fase vegetatifnya 65 hari [7].

\section{Sensor Ultrasonik HC-SR04}

Sensor ultrasonic HC-SR04 merupakan sensor pengukur jarak berbasis gelombang ultrasonik. Sensor ini berkerja dengan memanfaatkan pantulan gelombang ultrasonik. Jarak antara waktu pancar dan waktu terima adalah representasi dari jarak objek.

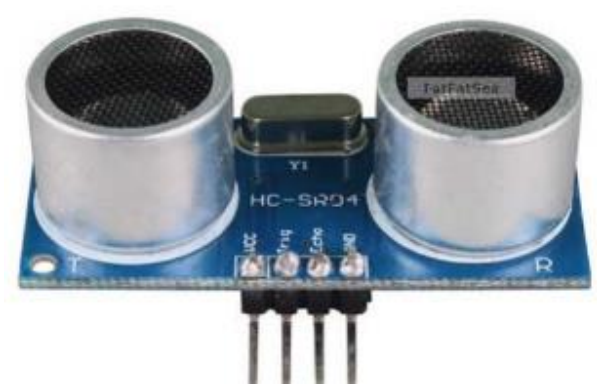

Gambar 2.1 Sensor Ultrasonik [8]

\section{Motor Servo DS04 NFC}

Motor servo DS04 NFC merupakan motor servo dengan contiuous rotation yang dioperasikan menggunakan pulsa PWM. Signal yang diguakan untuk mengendalikan motor servo adalah CW (clockwise/searah jarum jam), CCW (counter clockwise/berlawanan arah jarum jam) dan STOP. Duty cycle yang digunakan, yaitu 2000 (CW), 1000 (CCW) dan 1500 (STOP). Motor servo continuous rotation sering dipakai untuk Mobile Robot [9].

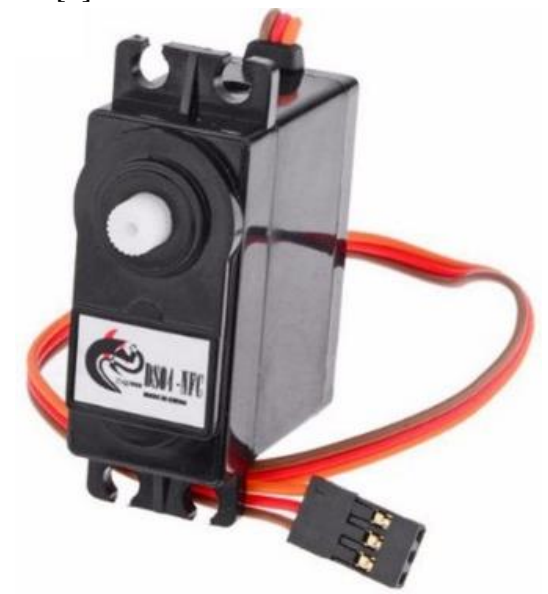

Gambar 2.2 Motor Servo DS04 NFC [9] 
Android

Android adalah sistem operasi yang berbasis Linux untuk telepon seluler seperti telepon pintar dan komputer tablet. Android menyediakan platform terbuka bagi para pengembang untuk menciptakan aplikasi mereka sendiri untuk digunakan oleh bermacam peranti bergerak. Awalnya, Google Inc. membeli Android Inc., pendatang baru yang membuat peranti lunak untuk ponsel [10]. Kemudian untuk mengembangkan android, dibentuklah Open Handset Alliance, konsorsium dari 34 perusahaan peranti keras, peranti lunak, dan telekomunikasi, termasuk Google, HTC, Intel, Motorola, Qualcomm, T-Mobile, dan Nvidia.

\section{7. $\quad$ Arduino Uno}

Arduino Uno adalah arduino board yang menggunakan mikrokontroler ATmega328. Arduino Uno memuat segala hal yang dibutuhkan untuk mendukung sebuah mikrokontroler. Hanya dengan menhubungkannya ke sebuah komputer melalui USB atau memberikan tegangan DC dari baterai atau adaptor AC ke DC sudah dapat membuatnya bekerja. Arduino Uno menggunakan ATmega16U2 yang diprogram sebagai USBtoserial converter untuk komunikasi serial ke komputer melalui port USB. Tampak atas dari arduino uno dapat dilihat pada Gambar 2.3 [11].

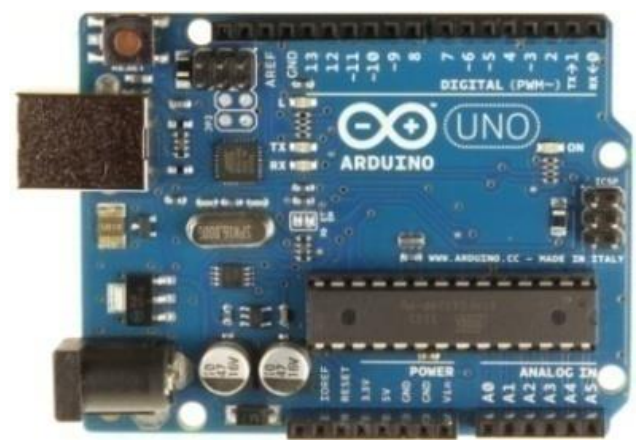

Gambar 2.3 Arduino Uno [11]

\section{8. $\quad$ ESP8266}

ESP8266 adalah sebuah modul wifi dengan output serial TTL yang sudah lengkap yang di dalamnya terdapat prosesor, memori dan akses ke General-Purpose Input/Output (GPIO). Karena kelengkapannya tersebut, ESP8266 dapat diprogram secara langsung tanpa modul mikrokontroler tambahan. Fungsi input/output dapat dilakukan melalui GPIO yang terdapat pada ESP8266. ESP8266 dapat berperan sebagai access point ataupun sebagai client. Ada beberapa jenis ESP8266 yang dapat ditemui di pasaran, namun yang paling mudah didapatkan di Indonesia adalah tipe ESP8266-01, ESP8266-07 dan ESP8266-12 dengan fungsi yang sama. Perbedaannya hanya terletak pada banyaknya GPIO yang disediakan [12].

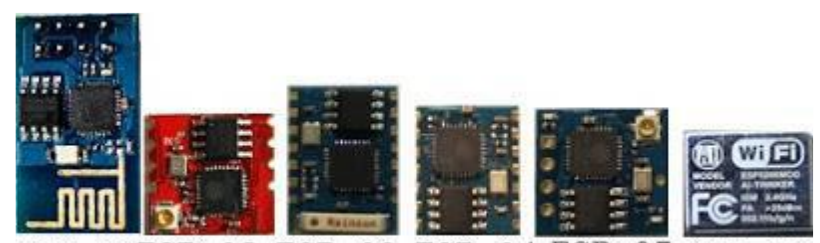

ESP-01ESP-02 ESP-03 ESP-04 ESP-05 ESP-06

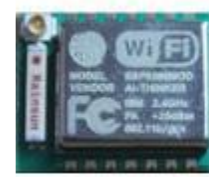

$\mathrm{ESP}-07$

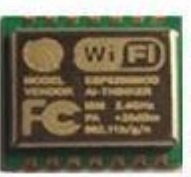

ESP-08

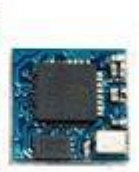

ESP-09 ESP-10 ESP-11

\section{Internet of Things (IoT)}

Internet of Things atau dikenal juga dengan singkatan IoT, merupakan sebuah konsep yang bertujuan untuk memperluas manfaat dari konektivitas internet yang tersambung secara terusmenerus. Dengan semakin berkembangnya infrastruktur internet, maka kita menuju babak berikutnya, di mana bukan hanya smartphone atau komputer saja yang dapat terkoneksi dengan internet. Namun berbagai macam benda nyata akan terkoneksi dengan internet. Sebagai contohnya dapat berupa mesin produksi, mobil, peralatan elektronik, peralatan yang dapat dikenakan manusia (wearables), dan termasuk benda nyata apa saja yang semuanya tersambung ke jaringan lokal dan global menggunakan sensor dan atau aktuator yang tertanam[13].

Sebagian petanian di dunia sudah mulai memanfaatkan teknologi informasi dan komunikasi (TIK) untuk membantu pengelolaan lahan pertanian. Para petani sudah ada yang menggunakan perangkat elektronik dan sensor untuk menyalakan dan mematikan sistem pengairan, melakukan pemantauan kondisi tanah, air cuaca serta membantu ketika panen. Teknologi ini memanfaatkan jejaring sensor yang terkoneksi dengan internet (IoT). IoT membuat pertanian semakin cerdas yang biasa disebut dengan sistem pertanian cerdas (smart farming) [14].

\section{Real-Time Clock (RTC) DS1307}

Real-time clock DS1307 merupakan komponen elektonika meyimpan data-data detik, menit, jam, tanggal dan bulan dalam seminggu, dan tahun valid hingga 2100. RTC DS1307 memiliki 56 byte NV SRAM. Data akan ditransfer secara serial melalui bus dua arah. Sinyal keluaran RTC DS1307. yaitu gelombang-kotak terprogram (Programmable squarewave).. Ketahanan komponen terhadap suhu $-40^{\circ} \mathrm{C}$ hingga $+85^{\circ} \mathrm{C}$ dan memiliki konsumsi daya kurang dari $500 \mathrm{nA}[15]$. 


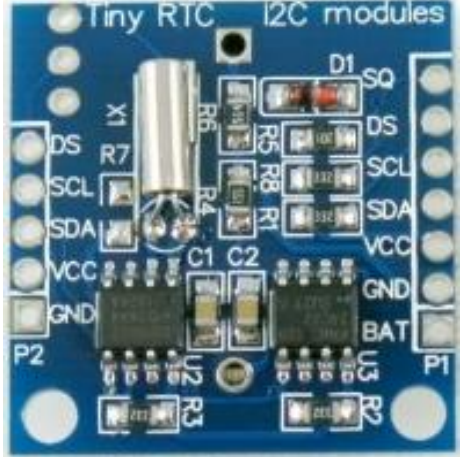

Gambar 2.5 RTC DS1307

\section{Pengukuran Tinggi Air}

Gelombang ultrasonik merupakan gelombang akustik yang memiliki frekuensi mulai $20 \mathrm{kHz}$ hingga sekitar $20 \mathrm{MHz}$. Frekuensi kerja yang digunakan dalam gelombang ultrasonik bervariasi tergantung pada medium yang dilalui, mulai dari kerapatan rendah pada fasa gas, cair hingga padat. Jika gelombang ultrasonik berjalan melalui sebuah medium. Secara matematis besarnya jarak dapat dihitung sebagai berikut:

$$
\begin{aligned}
& \mathrm{s}=\mathrm{v} \mathrm{x} \mathrm{t/2} \\
& \mathrm{s}=340 \times \mathrm{t} / 2
\end{aligned}
$$

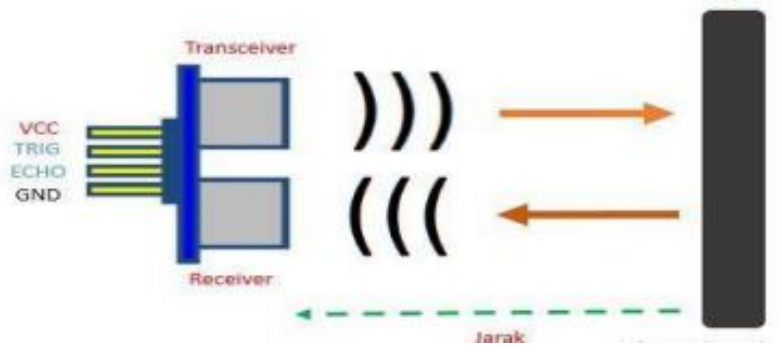

Gambar 2.6 Pengukuran Jarak antara Sensor dengan Objek [16]

Dimana s adalah jarak sensor dengan objek, v adalah kecepatan suara yaitu $340 \mathrm{~m} /$ detik dan $\mathrm{t}$ adalah waktu tempuh dalam satuan detik. Pada Gambar 2.9 ketika gelombang ultrasonik menumbuk suatu penghalang maka sebagian gelombang tersebut akan dipantulkan sebagian diserap dan sebagian yang lain akan diteruskan [17]. Untuk mengukur tinggi air dapat dihitung sebagai berikut:

$$
\mathrm{Ta}=\mathrm{Tmax}-\mathrm{s}
$$

Dimana Ta adalah tinggi air maksimal, Tmax adalah jarak sensor dasar tabung dan s adalah jarak sensor dengan objek[18].

\section{PERANCANGAN SISTEM}

\section{Analisa Kebutuhan Fungsional}

Pada bagian ini akan dijelaskan mengenai gambaran umum dari perancangan sistem yang akan dibangun. Berikut ini beberapa fungsionalita sistem yang harus dipenuhi, yaitu :

1. Sistem dapat mengatur kadar air yang terdapat dalam sawah sesuai dengan metode yang diterapkan berdasarkan usia tanaman padi dengan satuan Hari Setelah Tanam (HST) dan input yang diterima dari sensor.

2. Sistem dapat mengatur pintu masuk dan keluar air berdasarkan kadar air di lahan sawah.
3. User dapat menginputkan usia tanaman padi dan menonaktifkan sistem melalui aplikasi mobile pada smartphone user.

\section{Analisa Kebutuhan Non-Fungsional}

Kebutuhan non-fungsional dari sistem pengatur irigasi sawah ini adalah kecepatan konektifitas internet yang digunakan pada sistem. Kecepatan internet tergantung pada kecepatan jaringan di wilayah tersebut.

\section{Perancangan Arsitektur}

Perancangan arsitektur dilakukan dengan menggambarkan rancangan hardware sistem secara keseluruhan. Berikut gambar rancangan arsitektur sistem pengatur irigasi sawah:

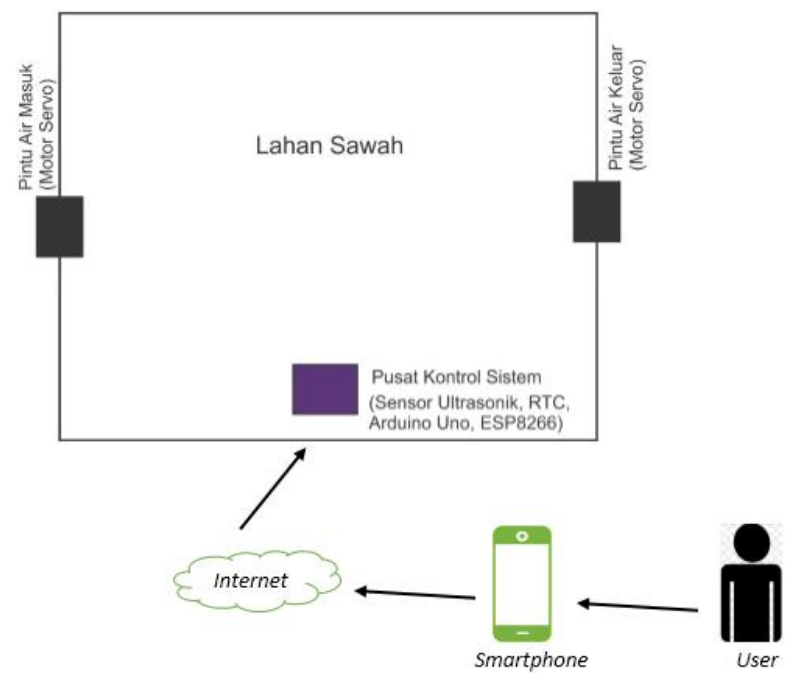

Gambar 3.1 Perancangan Arsitektur

Gambar 3.2 merupakan rancangan arsitektur sistem pengatur irigasi sawah. Sistem pengatur irigasi terdiri dari komponen hardware, yaitu arduino uno, RTC, sensor ultrasonik, motor servo dan ESP8266. Komponen hardware tersebut akan terhubung ke mobile application menggunakan modul ESP8266. Sistem dapat mengatur irigasi sawah secara otomatis dan user meng-input-kan usia tanaman padi melalui aplikasi mobile (smartphone).

\section{Perancangan Proses}

Proses pada sistem pengatur irigasi sawah dimulai dengan menginputkan data usia tanaman padi pada aplikasi mobile. Pada pemrograman arduino uno, dilakukan pendeklarasian variabel sensor ultrasonik, motor servo, usia tanaman padi. Sistem dijalankan jika usia tanaman padi yang diinputkan besar dari 0 . Usia tanaman padi IR64 sampai hari panen yang diimplementasikan pada sistem adalah 120 HST. Jika usia tanaman padi antara 1-119 HST, maka arduino menjalankan sistem pengatur irigasi sawah berdasarkan usia tanaman padi yang dihitung berdasarkan data waktu RTC dan tinggi air yang diukur oleh sensor. Untuk mengukur tinggi air di lahan sawah, data yang di diterima dari sensor ultrasonik akan dikonversi ke dalam satuan jarak $(\mathrm{cm})$. Berdasarkan data usia padi dan tinggi air di lahan sawah, dilakukan pemberian dan pengeluaran air, dengan cara menggerakkan pintu air menggunakan motor servo yang berotasi untuk membuka pintu dan menutup pintu. Jika user 
mengirim perintah nonaktif sistem melalui aplikasi mobile pada halaman Nonaktif Sistem dimana usia yang dikirim adalah 300, maka sistem di nonaktifkan sementara sampai usia tanaman padi di-input-kan dari aplikasi mobile oleh user dengan rentang usia adalah 1-119 HST. Ketika usia tanaman padi sama dengan 120 HST sistem pengatur irigasi selesai.

Pada sistem pengatur irigasi sawah ini, jadwal pengisian air ke lahan sawah berdasarkan kadar air di lahan sawah. Sedangkan kadar air di lahan sawah diatur berdasarkan usia tanaman padi. Untuk menggerakkan pintu air, motor servo akan berotasi menggerakkan pintu air berdasarkan data tinggi air yang dibaca oleh sensor ultrasonik. Saat tinggi air yang dideteksi oleh sensor mencapai batas minimal, maka motor servo akan berotasi untuk membuka pintu air masuk. Pintu air masuk dibuka sampai tinggi air di lahan sawah mencapai batas maksimal. Apabila tinggi air yang dideteksi oleh sensor melebihi batas maksimal, maka motor servo akan berotasi untuk membuka pintu air keluar. Pintu air keluar dibuka sampai tinggi air sama dengan batas maksimal

\section{Perancangan Perangkat Lunak}

Berikut tampilan antarmuka dari aplikasi mobile dapat dilihat pada gambar 3.2 di bawah ini:
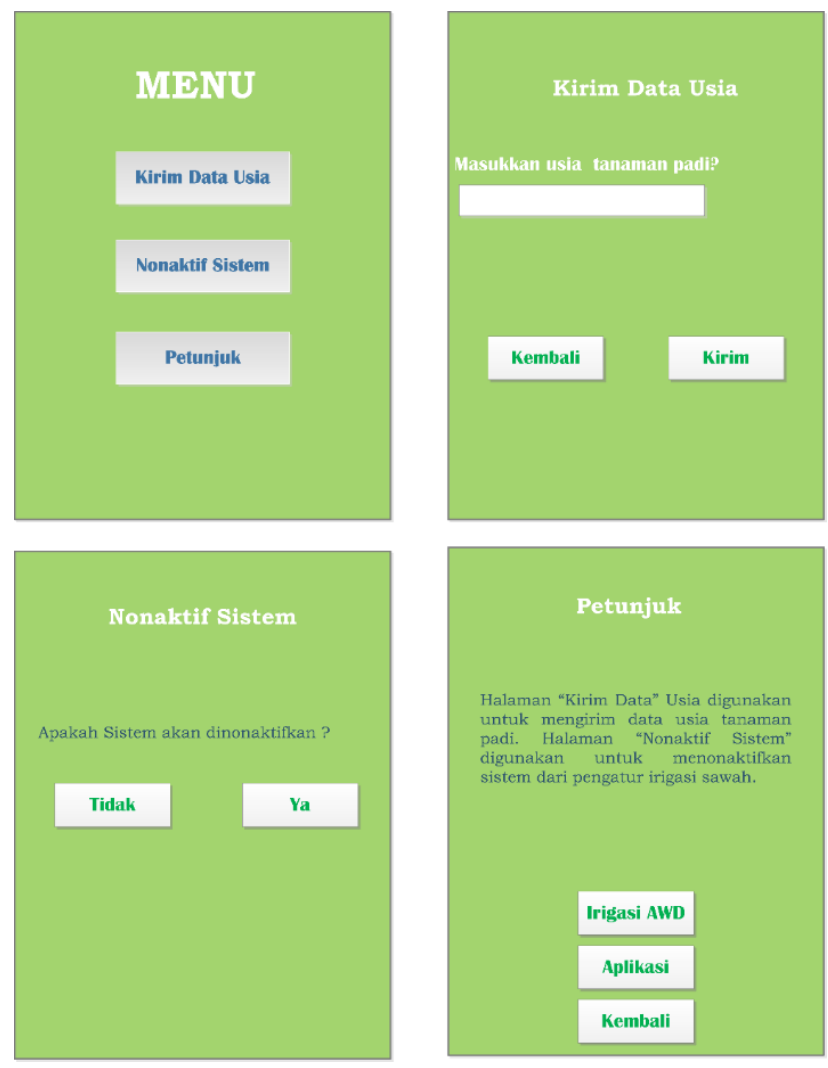

Gambar 3.2 Tampilan Aplikasi Mobile

\section{HASIL DAN ANALISA}

\section{Implementasi Perangkat Keras}

Sistem Pada implementasi perangkat keras dirancang secara terpisah yang terdiri dari 3 bagian yaitu, pintu air masuk, pintu air keluar dan pusat kontrol sistem. Pintu air masuk dan keluar dirancang seperti parit kecil menggunakan akrilik yang memiliki ketebalan $5 \mathrm{~mm}$ berwarna hitam dengan ukuran $20 \mathrm{~cm} \quad 11 \mathrm{~cm}$ $20 \mathrm{~cm}$. Bagian penghalang air di dalam parit menggunakan akrilik dengan luas $11 \mathrm{~cm} 10 \mathrm{~cm}$. Motor DS04 NFC dipasang pada besi pita yang di pasang pada bagian sisi parit dengan ketinggian 42 $\mathrm{cm}$. Motor dihubungkan dengan pintu penghalang air menggunakan baut bangunan dengan panjang $20 \mathrm{~cm}$ dan 2 buah besi yang dipasang pada motor dan akrilik ukuran $4 \mathrm{~cm} 4 \mathrm{~cm}$ yang di lem pada mur baut bangunan. Sedangkan untuk pusat kontrol sistem komponen elekronika seperti mikrokontroler Arduino Uno, RTC DS1307, ESP8266 dan sensor ultrasonik di pasang pada kotak berukuran $16 \mathrm{~cm} \quad 16 \mathrm{~cm} \quad 11 \mathrm{~cm}$. Kotak ini dipasang pada bagian atas kaki penyangga yang dirancang menggunakan besi siku dengan ketinggian $60 \mathrm{~cm}$. Pada Gambar 4.1 akan dilihatkan bentuk implementasi perangkat keras.
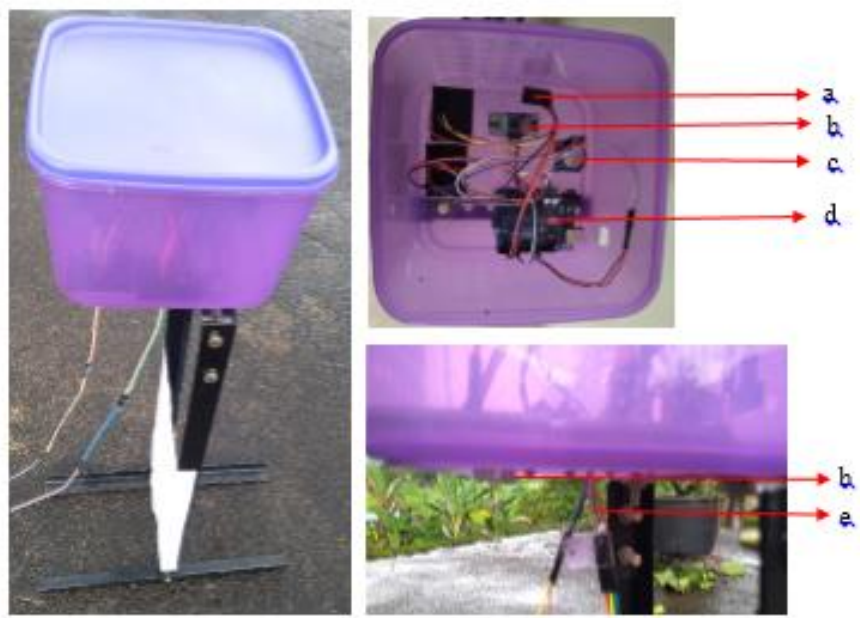

(a)

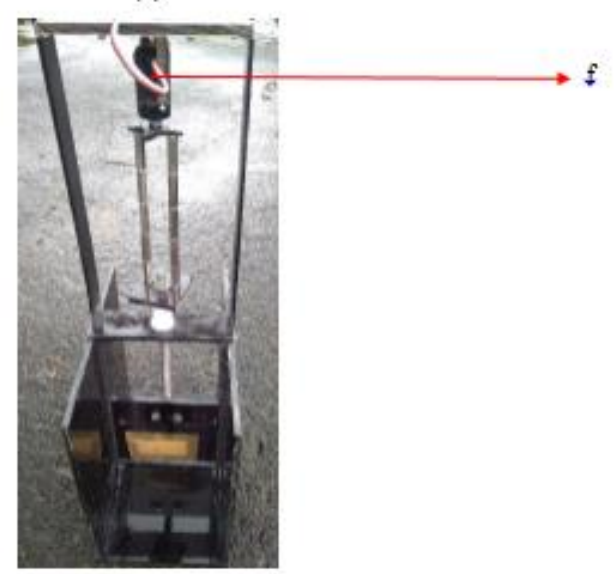

(b)

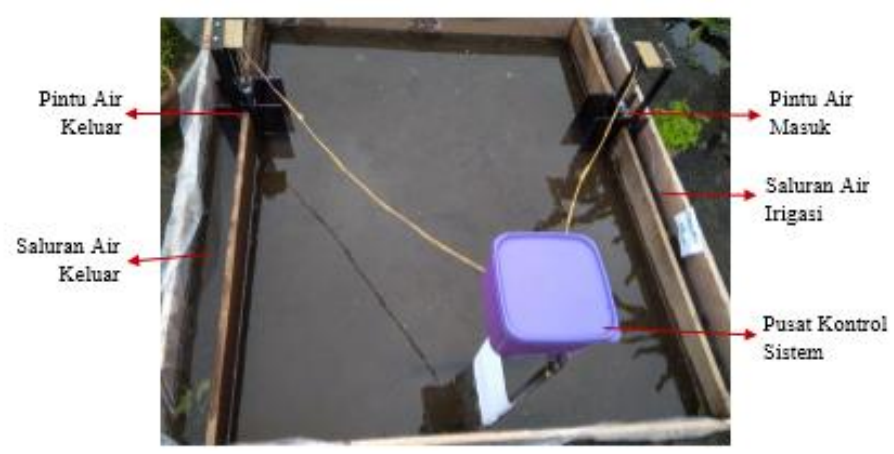

(c)

Gambar 4.1 Implementasi Perangkat keras

(a) Pusat Kontrol Sistem (b) Pintu Air (c) Miniatur Lahan Sawah 
Keterangan dan cara kerja komponen pada Gambar 4.1 sebagai berikut:

1. Modul ESP8266, berfungsi untuk menghubungkan sistem tertanam arduino dengan internet.

2. Sensor ultrasonik berfungsi sebagai pengukur tinggi air.

3. RTC DS1307 digunakan membaca waktu secara real time.

4. Arduino Uno, berfungsi untuk mengontrol kerja sistem.

5. Jumper, berfungsi untuk menghubungkan motor servo pada pintu air dengan arduino uno.

6. Motor servo DS04 NFC, berfungsi untuk menggerakkan pintu air masuk dan keluar.

\section{Implementasi Sistem}

Implementasi input usia tanaman padi sangat dibutuhkan untuk menjalankan sistem sesuai dengan usia tanaman padi. Implementasi ini digunakan saat sistam baru akan dijalankan dan saar sistem akan diaktifkan kembali setelah dinonaktifkan sementara. Usia tanaman padi di-input-kan dari aplikasi mobile pada halaman Kirim Data Usia. Berikut potongan program input pada app inventor dapat dilihat pada Gambar 4.2.

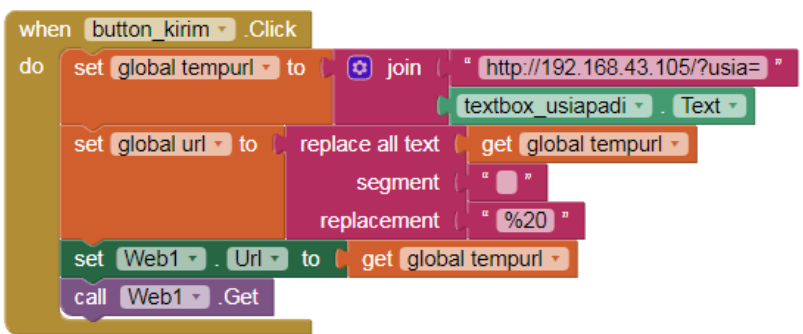

(a)

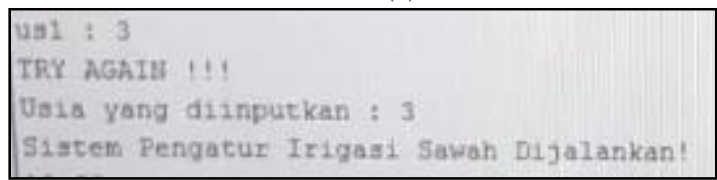

(b)

Gambar 4.2 (a) Program Input pada App Inventor

(b) Tampilan Input yang Diterima pada Serial Monitor

Pada Gambar 4.2 saat button kirim di tekan pada aplikasi mobile nilai input akan dikirim langsung ke arduino dengan menggunakan IP Address modul wifi. Nilai yang masuk pada modul wifi akan dibaca oleh arduino

\section{Pengujian Input Usia untuk \\ Mengaktifkan Kerja Sistem}

Pengujian ini dilakukan untuk mengetahui kemampuan sistem dalam menerima input yang dikirim dari aplikasi mobile. Pengujian ini sangat penting dilakukan untuk membantu sistem dalam mengontrol tinggi air di lahan sawah saat sistem baru dijalankan atau ketika sistem dinonaktifkan sementara pada kondisi tertentu.
Tabel 4.1 Pengujian Input Usia Tanaman Tadi

\begin{tabular}{|c|c|c|c|c|}
\hline $\begin{array}{c}\text { Percobaan } \\
\text { ke- }\end{array}$ & $\begin{array}{c}\text { Data dikirim } \\
\text { (Smartphone) }\end{array}$ & $\begin{array}{c}\text { Data } \\
\text { diterima } \\
\text { (Arduino) }\end{array}$ & $\begin{array}{c}\text { Kesamaan } \\
\text { Data }\end{array}$ & Keberhasilan \\
\hline 1 & 4 & -49 & Tidak & Gagal \\
\hline 2 & 1 & 1 & Sama & Berhasil \\
\hline 3 & 10 & 10 & Sama & Berhasil \\
\hline 4 & 25 & -49 & Tidak & Gagal \\
\hline 5 & 34 & 34 & Sama & Berhasil \\
\hline 6 & 50 & -49 & Tidak & Gagal \\
\hline 7 & 5 & 5 & Sama & Berhasil \\
\hline 8 & 44 & 44 & Sama & Berhasil \\
\hline 9 & 27 & 27 & Sama & Berhasil \\
\hline 10 & 12 & 12 & Sama & Berhasil \\
\hline
\end{tabular}

Hasil pengujian input usia memiliki persentase keberhasilan sebesar:

Persentase keberhasilan $=\frac{(\text { Jumlah berhasil })}{(\text { Jumlah percobaan })} \times 100 \%$

Persentase keberhasilan $=\frac{7}{10} \times 100 \%$

Persentase keberhasilan $=70 \%$

Persentase keberhasilan pengujian sebesar $70 \%$ dan error yang didapat adalah $30 \%$. Error ini disebabkan oleh kurang baiknya jaringan internet saat pengujian.

\section{Pengujian Kontrol Tinggi Air Secara Otomatis}

Pengujian ini dilakukan untuk mengetahui kemampuan sistem dalam mengatur tinggi air di lahan sawah. Pengujian ini berdasarkan usia tanaman, tinggi air, pintu air masuk dan pintu air keluar. Usia tanaman padi digunakan untuk memilih kondisi tinggi air. Tinggi air diukur oleh sensor ultrasonik. Kontrol pintu air masuk dan keluar berdasarkan usia dan tinggi air.

Kondisi tinggi air pada metode irigasi AWD ditetapkan berdasarkan usia tanaman. Berikut kelompok usia tanaman padi dan batas tinggi air pada masing-masing kelompok usia dapat dilihat pada Tabel 4.2.

Tabel 4.2 Kelompok Usia Tanaman Padi dan Batas Tinggi Air

\begin{tabular}{|c|c|c|}
\hline $\begin{array}{c}\text { Kelompok } \\
\text { Usia }\end{array}$ & $\begin{array}{c}\text { Kondisi } \\
\text { Irigasi }\end{array}$ & $\begin{array}{c}\text { Batas Tinggi Air } \\
\text { (dimulai dari 15 cm dibawah } \\
\text { permukaan tanah) }\end{array}$ \\
\hline $1-7$ HST & Tergenang & $15 \mathrm{~cm}-17 \mathrm{~cm}$ \\
\hline $8-48$ HST & AWD & $1 \mathrm{~cm}-17 \mathrm{~cm}$ \\
\hline $111-120 \mathrm{HST}$ & Kering & - \\
\hline
\end{tabular}

Pengujian dilakukan dengan melihat respon sistem terhadap tinggi air di lahan. Pada pengujian ini, tabung dibenamkan sedalam $7.5 \mathrm{~cm}$ untuk mengukur tinggi air dibawah permukaan tanah. Hasil pengukuran akan dikali 2 agar sesuai dengan perhitungan tinggi air yang telah ditetapkan. Hasil Pengujian dapat dilihat pada Tabel 4.3. 
Tabel 4.3 Pengujian Kontrol Tinggi Air

\begin{tabular}{|c|c|c|c|c|c|c|c|c|c|}
\hline \multirow{2}{*}{$\begin{array}{l}\text { Perco- } \\
\text { baan }\end{array}$} & \multirow{2}{*}{$\begin{array}{l}\text { Data } \\
\text { lye- }\end{array}$} & \multirow{2}{*}{$\begin{array}{c}\text { Usia } \\
\text { Tanaman } \\
\text { Padi } \\
\text { (HST) }\end{array}$} & \multirow{2}{*}{$\begin{array}{c}\text { Kelompolk } \\
\text { Usia }\end{array}$} & \multirow{2}{*}{$\begin{array}{l}\text { Kondisi Air } \\
\text { di Lahan } \\
\text { Sawah }\end{array}$} & \multirow{2}{*}{$\begin{array}{l}\text { Tinggi Air } \\
\text { Pengu- } \\
\text { luran } \\
\text { Sensor } \\
\text { (cm) }\end{array}$} & \multicolumn{2}{|c|}{$\begin{array}{l}\text { Altivasi Pintu } \\
\text { Air }\end{array}$} & \multirow{2}{*}{ Jenis Error } & \multirow{2}{*}{$\begin{array}{l}\text { Tinglat } \\
\text { Keber- } \\
\text { hasilan }\end{array}$} \\
\hline & & & & & & $\begin{array}{c}\text { Pintu } \\
\text { Air } \\
\text { Masulk }\end{array}$ & $\begin{array}{c}\text { Pintu } \\
\text { Air } \\
\text { Keluar }\end{array}$ & & \\
\hline \multirow{9}{*}{ I } & 1 & 2 & \multirow{9}{*}{ Tergenang } & $\begin{array}{c}\text { Dibawah } \\
\text { batas } \\
\text { nuinimal } \\
\text { (pengisinn } \\
\text { air) }\end{array}$ & 14.66 & Buba & Tutup & Tidals Ada & Berhasil \\
\hline & 2 & 3 & & $\begin{array}{l}\text { Normal } \\
\text { (pengisian } \\
\text { air) }\end{array}$ & 17.06 & Tutup & Tutup & $\begin{array}{l}\text { Pengularan } \\
\& \text { Tutup } \\
\text { Pintu Air } \\
\text { Masulk }\end{array}$ & Gagl \\
\hline & 3 & 4 & & Normal & 15.34 & Tutup & Tutup & Tidnk Ada & Berhasil \\
\hline & 4 & 5 & & Normal & 15.27 & Tunp & Tutup & Tidals Ada & Berhasil \\
\hline & 5 & 6 & & Normal & 15.31 & Tunup & Tutup & Tidak Ada & Berhasil \\
\hline & 6 & 7 & & Normal & 15.38 & Tunup & Tutup & Tidak Ada & Berhasil \\
\hline & 7 & 8 & & Normal & 14.42 & Bula & Tutup & $\begin{array}{l}\text { Pengularan } \\
\text { \& Bula } \\
\text { Pintu Air } \\
\text { Magulk }\end{array}$ & Gagl \\
\hline & 8 & 9 & & $\begin{array}{l}\text { Normal } \\
\text { (pengisinn } \\
\text { air) }\end{array}$ & 15.93 & Buba & Tutup & Tidals Ada & Berhasil \\
\hline & 9 & 10 & & $\begin{array}{l}\text { Normul } \\
\text { (pengisinn } \\
\text { air) }\end{array}$ & 15.72 & Buba & Tutup & Tidak Ada & Berhasil \\
\hline \multirow{9}{*}{ II } & 1 & 11 & \multirow{9}{*}{ AWD } & $\begin{array}{c}\text { Dibawah } \\
\text { batas } \\
\text { minimal } \\
\text { (pengisian } \\
\text { äi) }\end{array}$ & -3.48 & Bula & Tutup & Pengularan & $\begin{array}{l}\text { Culsup } \\
\text { Berhasi }\end{array}$ \\
\hline & 2 & 12 & & $\begin{array}{l}\text { Dibawah } \\
\text { batas } \\
\text { minimal } \\
\text { (pengisinn } \\
\text { air) }\end{array}$ & -2.58 & Bula & Tutup & Pengularan & $\begin{array}{l}\text { Culap } \\
\text { Berhasi }\end{array}$ \\
\hline & 3 & 13 & & $\begin{array}{l}\text { Dibawah } \\
\text { batas } \\
\text { minimal } \\
\text { (pengisian } \\
\text { air) } \\
\end{array}$ & -2.21 & Bulba & Tutup & Pengularan & $\begin{array}{l}\text { Culap } \\
\text { Berhasil }\end{array}$ \\
\hline & 4 & 14 & & Normal & 2.64 & Turup & Tunup & Tidak Ada & Berhasil \\
\hline & 5 & 15 & & Normal & 26.35 & Tutup & Buba & $\begin{array}{l}\text { Pengularian } \\
\& \text { Buka } \\
\text { Pintu Air } \\
\text { Kehuar }\end{array}$ & Gagl \\
\hline & 6 & 16 & & Normal & -3.92 & Tutup & Tutup & Pengularan & $\begin{array}{l}\text { Culamp } \\
\text { Berhasi }\end{array}$ \\
\hline & 7 & 17 & & Normal & 25.56 & Tutup & Bulka & $\begin{array}{l}\text { Pengularian } \\
\& \text { Bula } \\
\text { Pintu Air } \\
\text { Kehuar }\end{array}$ & Gagl \\
\hline & 8 & 18 & & Normal & 0.82 & Tutup & Tutup & Tidak Ada & Berhasil \\
\hline & 9 & 19 & & Normal & 30.44 & Tunup & Bulba & $\begin{array}{c}\text { Pengularanan } \\
\& \text { Buka } \\
\text { Pintu Air } \\
\text { Kehuar } \\
\end{array}$ & Gagl \\
\hline \multirow{9}{*}{ III } & 1 & 112 & \multirow{9}{*}{ Kering } & - & - & Tutup & Bula & Tidak Ada & Berhasil \\
\hline & 2 & 113 & & - & - & Tutup & Bulka & Tidak Ada & Berhasil \\
\hline & 3 & 114 & & - & - & Tutup & Bula & Tidak Ada & Berhasil \\
\hline & 4 & 115 & & - & - & Tutup & Bula & Tidak Ada & Berhasil \\
\hline & 5 & 116 & & - & - & Tutup & Bula & Tidalk Ada & Berhasil \\
\hline & 6 & 117 & & - & - & Tutup & Buka & Tidak Ada & Berhasil \\
\hline & 7 & 118 & & - & - & Tutup & Bulaa & Tidak Ada & Berhasil \\
\hline & 8 & 119 & & - & - & Tutup & Bulka & Tidak Ada & Berhasil \\
\hline & 9 & 120 & & - & - & Tutup & Bulaa & Tidalk Ada & Berhasil \\
\hline
\end{tabular}


Dari hasil pengujian pada Tabel 4.3 diketahui bahwa pada pengujian ini terdapat dua jenis error, yaitu error pengukuran, error pengukuran dan aktivasi pintu air masuk dan error pengukuran dan aktivasi pintu air keluar. Persentase keberhasilan pengujian ini adalah:

Persentase keberhasilan $=\frac{(\text { Jumlah berhasil }+ \text { cukup berhasil })}{\text { (Jumlahpercobaan })} \quad \mathrm{x}$ $100 \%$

Persentase keberhasilan $=\frac{22}{27} \times 100 \%$

Persentase keberhasilan $=81.48 \%$

Persentase keberhasilan yang dimasukkan adalah tingkat keberhasilan yang dikategorikan Berhasil dan Cukup Berhasil. Tingkat keberhasilan pengujian pada kategori Cukup Berhasil, error hanya terjadi pada pengukuran tinggi air dan tidak mempengaruhi aktivasi pintu air. Persentase keberhasilan pengujian sebesar $81.48 \%$ menunjukkan keakuratan sistem dalam mengontrol pintu air. Error yang didapatkan pada pengujian ini adalah $18.52 \%$.

\section{Pengujian Nonaktif Sistem Sementara Melalui Aplikasi Mobile}

Pengujian ini dilakukan untuk mengetahui kemampuan sistem dalam menerima perintah nonaktif sementara dari aplikasi mobile. Perintah dikirim user melalui halaman Nonaktif Sistem pada aplikasi mobile. Hasil Pengujian dapat dilihat pada Tabel berikut.

Tabel 4.4 Pengujian Nonaktif Sistem

\begin{tabular}{|c|c|c|c|}
\hline $\begin{array}{c}\text { Percobaan } \\
\text { ke- }\end{array}$ & $\begin{array}{c}\text { Perintah } \\
\text { dikirm }\end{array}$ & $\begin{array}{c}\text { Perintah } \\
\text { Diterima }\end{array}$ & Keberhasilan \\
\hline 1 & Ada & Ada & Berhasil \\
\hline 2 & Ada & Tidak & Gagal \\
\hline 3 & Ada & Ada & Berhasil \\
\hline 4 & Ada & Tidak & Gagal \\
\hline 5 & Ada & Tidak & Gagal \\
\hline 6 & Ada & Ada & Berhasil \\
\hline 7 & Ada & Ada & Berhasil \\
\hline 8 & Ada & Ada & Berhasil \\
\hline 9 & Ada & Ada & Berhasil \\
\hline 10 & Ada & Ada & Berhasil \\
\hline
\end{tabular}

Hasil pengujian nonaktif sistem menghasilkan persentase keberhasilan sebesar:

Persentase keberhasilan $=\frac{(\text { Jumlah berhasil })}{(\text { Jumlah percobaan })} \times 100 \%$

Persentase keberhasilan $=\frac{7}{10} \times 100 \%$

Persentase keberhasilan $=70 \%$

Persentase keberhasilan yang didapatkan adalah $70 \%$ dengan error sebesar $30 \%$. Hal ini menunjukkan kemampuan sistem dalam menerima perintah nonaktif sistem cukup bagus.

\section{PENUTUP}

\section{Kesimpulan}

Berdasarkan perancangan, pengamatan, dan pengujian yang telah dilakukan, sistem pengatur irigasi sawah dapat bekerja dengan baik mengatur aktivasi pintu air masuk dan pintu air keluar. Hasil pengujian menunjukkan bahwa pengukuran tinggi air yang akurat dapat mengontrol aktivasi pintu air secara tepat. Tinggi air dilahan sawah dapat diatur menggunakan metode irigasi AWD. Keberhasilan metode irigasi AWD berdasarkan hasil pengujian yang telah dilakukan dengan persentase keberhasilan sebesar $81.48 \%$. Sistem dapat terhubung dengan internet untuk menerima input usia tanaman padi dan nonaktif sistem dari aplikasi mobile. Hal ini dapat ditunjukkan melalui hasil pengujian sistem dengan keberhasilan yang diperoleh adalah $70 \%$.

\section{Saran}

Karena masih banyak terdapat kekurangan pada penelitian ini, maka diberikan beberapa saran agar penelitian ini dapat dikembangkan lebih lanjut, yaitu:

1. Untuk penelitian selanjutnya, perlu dirancang sistem cerdas seperti fuzzy logic control untuk mengatur besar pintu air yang terbuka berdasarkan tinggi air, sehingga sistem dapat mengatur kadar air di lahan dengan akurat.

2. Untuk penelitian selanjutnya, sistem dapat diterapkan pada jenis padi yang lain.

3. Untuk penelitian selanjutnya, motor servo yang digunakan memiliki spesifikasi diatas motor servo DS04 NFC.

4. Untuk penelitian selanjutnya, modul wifi yang digunakan memiliki spesifikasi diatas ESP8266 agar komunikasi pada jaringan internet stabil.

5. Untuk penelitian selanjutnya, mikrokontroler yang digunakan memiliki keampuan lebih tinggi dari Arduino Uno seperti Arduino Mega, karena kapasitas memori yang digunakan pada penelitian saat ini sudah mencapai 60\%. Jika masih digunakan pada pengembangan selanjutnya dapat berpengaruh pada kestabilan program yang dijalankan.

\section{REFERENSI}

[1] Idris, Muhammad. 2017. "Beras di Urutan Pertama Pemicu Kemiskinan, Rokok Kedua". Detik. Jakarta. https://finance.detik.com/berita-ekonomi-bisnis/d3386684/beras-di-urutan-pertama-pemicu-kemiskinanrokok-kedua. diakses tanggal 17 Mei 2017

[2] Anonim. 2016. "Persentase Penduduk Miskin Maret 2016 Mencapai 10,86 Persen”. Badan Pusat Statistik. Jakarta https://www.bps.go.id/brs/view/id/1229. diakses tanggal 25 November 2016

[3] Taufik, Muh. dkk. 2014. Analisis Pengelolaan Air dalam Usaha Tani Padi pada Lahan Sawah Irigasi di Sulawesi Selatan. Pengkajian dan Pengembangan Teknologi Pertanian. 7(1):1-8.

[4] Adriati, Yolly. 2008. Kajian beberapa metode sistem pemberian sistem irigasi padi sawah. Jurnal Saintis.10 (2):1-12.

[5] Zulhakki dkk. 2013. Evaluasi beberapa metode penentuan nilai modulus drainase pada lahan sawah di daerah Desa Sei Beras Sekata Kecamatan Sunggal Kabupaten Deli Serdang. Ilmu dan Teknologi Pangan J.Rekayasa Pangan dan Pert. 1(2):78-82.

[6] Mariam, Siti.2013. Padi. Universitas Padjadjaran. Bandung.

[7] Makarim, A.K dan E. Suhartatik. 2009. Morfologi dan Fisiologi Tanaman Padi. Balai Besar Penelitian Tanaman Padi Balitbangtan. Jakarta.

[8] HC-SR04

Datasheet, http://www.electroschematics.com/wpcontent/uploads/2013/07/HCSR04-datasheet-version- 
$\underline{1 . p d f}$, diakses pada tanggal 15 Januari 2017 pada pukul 14.32

[9] Servo Motor Set Model: DS04-NFC, http://www.ekt 2.com/pdf/412_CH_SERVO_MOTOR_S ET.pdf, diakses tanggal 20 Oktober 2017 pada pukul $\underline{06.00}$

[10] Y. Supardi. 2011. Semua Bisa Menjadi Programmer Android Basic. Elex Media Komputindo. Jakarta.

[11] Simajuntak, M.G dan F. Rizal B. 2013. Perancangan prototipe smart building berbasis Arduino Uno. SIGUNDA ENSIKOM. 2(2):78-83.

[12] Karuna, Regine Giri, dkk. 2016. "Perancangan dan realisasi sistem presensi mahasiswa menggunakan kartu magnetik". SNTS II 2016. 1:1-14.

[13] Arafa. 2016. "Sistem pengamanan pintu rumah berbasis Internet of Things (IoT) dengan ESP8266". Technologia. 7(4):1-7.

[14] L. Ventje J. dkk. 2016. "Model Inferensi Konteks Internet of Things pada Sistem Pertanian Cerdas". Telematika. 11(2):49-54.

[15] RTC DS1307 Datasheet, https://datasheets.maximintegrated.com/en/ds/DS1307.p df, diakses tanggal 12 Juni 2017 pada pukul 10.27

[16] Arasada, Bakhtiyar dan Bambang Suprianto. 2017. “Aplikasi Sensor Ultrasonik Untuk Deteksi Posisi Jarak Pada Ruang Menggunakan Arduino Uno”. Teknik Elektro Universitas Negeri Surabaya. 6(2):137-145.

[17] Arief, Ulfah Mediaty. 2011. "Pengujian Sensor Ultrasonik PING untuk Pengukuran Level Ketinggian dan Volume Air”. Elektrikal Enjiniring UNHAS. 9(2):7277.

[18] Rizki, Maidi dan Rahyul Amri. 2016. "Perancangan Kontrol dan Monitoring Level Ketinggian Air di Waduk Bagian Hulu Untuk Meningkatkan Efektifitas Kinerja PLTA Koto Panjang”. Jom FTEKNIK. 3(1):1-6. 